\title{
Diversity of endophytic fungal community associated with Piper hispidum (Piperaceae) leaves
}

\author{
R.C. Orlandelli ${ }^{1}$, R.N. Alberto ${ }^{1}$, C.J. Rubin Filho ${ }^{2}$ and J.A. Pamphile ${ }^{1}$ \\ ${ }^{1}$ Departamento de Biologia Celular e Genética, \\ Universidade Estadual de Maringá, Maringá, PR, Brasil \\ ${ }^{2}$ Departamento de Biologia, Universidade Estadual de Maringá, Maringá, \\ PR, Brasil \\ Corresponding author: J.A. Pamphile \\ E-mail: prof.pamphile@gmail.com
}

Genet. Mol. Res. 11 (2): 1575-1585 (2012)

Received October 13, 2011

Accepted April 20, 2012

Published May 22, 2012

DOI http://dx.doi.org/10.4238/2012.May.22.7

\begin{abstract}
Tropical and subtropical plants are rich in endophytic community diversity. Endophytes, mainly fungi and bacteria, inhabit the healthy plant tissues without causing any damage to the hosts. These fungi can be useful for biological control of pathogens and plant growth promotion. Some plants of the genus Piper are hosts of endophytic microorganisms; however, there is little information about endophytes on Piper hispidum, a medicinal shrub used as an insecticide, astringent, diuretic, stimulant, liver treatment, and for stopping hemorrhages. We isolated the fungal endophyte community associated with $P$. hispidum leaves from plants in a Brazilian forest remnant. The endophytic diversity was examined based on sequencing of the ITS1-5.8S-ITS2 region of rDNA. A high colonization frequency was obtained, as expected for tropical angiosperms. Isolated endophytes were divided into 66 morphogroups, demonstrating considerable diversity. We identified 21 isolates, belonging to 11 genera (Alternaria, Bipolaris, Colletotrichum, Glomerella, Guignardia, Lasiodiplodia, Marasmius, Phlebia, Phoma, Phomopsis, and Schizophyllum); one isolate was identified only to the order level (Diaporthales). Bipolaris was the most
\end{abstract}


frequent genus among the identified endophytes. Phylogenetic analysis confirmed the molecular identification of some isolates to genus level while for others it was confirmed at the species level.

Key words: Endophytes; Piperaceae; Molecular identification; rDNA sequencing; Phylogeny

\section{INTRODUCTION}

The medicinal plant Piper hispidum Swartz (Piperaceae family) is a shrub distributed throughout the Antilles, and Central and South America, including all Brazilian geographic regions (Guimarães and Giordano, 2004). It is commonly known as "platanillo-de-cuba" and "bayuyo" (Cuba), "cordoncillo" (Mexico), "jaborandi" and "falso-jaborandi" (Brazil) and its properties include use as an astringent, diuretic, stimulant, for unblocking the liver, and stopping hemorrhages (Roíg y Mesa, 1945).

It is reported that other Piper species, such as $P$. barbatum and $P$. nigrum, are hosts of endophytic microorganisms (Yandry et al., 2006; Aravind et al., 2009) that inhabit healthy plant tissues, which after infection remain at least transiently symptomless (Ding et al., 2010). Endophytes are useful in the biological control of pathogens or plant growth promotion; nevertheless, some of them are commensal species that cause no direct effect on the host plants (Procópio et al., 2009).

The largest diversity of endophytic species can be found in tropical and subtropical rainforests because these ecosystems are the richest in plant diversity (Banerjee, 2011). Endophyte-plant interactions become more complex in regions with a greater variety of organisms (Pamphile et al., 2004) and include a co-evolution process involving endophytic isolates and the host plants, as shown by Pamphile and Azevedo (2002). Endophytic fungi can be associated with inter- and intracellular colonization of plant host tissues (Bernardi-Wenzel et al., 2010).

Most studies have focused on foliar endophytes, since they are especially diverse and abundant (Arnold et al., 2000). Ecologically relevant roles of tropical foliar endophytic fungi have been demonstrated, such as the physiological costs in terms of water relations and photosynthesis (Pinto et al., 2000; Herre et al., 2005; Arnold and Engelbrecht, 2007) and antipathogen protection of hosts mediated by endophytes (Hanada et al., 2010; Rocha et al., 2011), indicating a defensive mutualism that can be detected by the control of natural herbivores and pathogens in laboratory and greenhouse experiments (Saikkonen and Helander, 2010).

Culture-dependent studies of endophytic fungi, those beginning with their isolation from surface-disinfected plant samples and cultivation on appropriate culture medium, have been widely employed (Araújo et al., 2001; Sánchez Márquez et al., 2007; Ding et al., 2010; González and Tello, 2011).

The sensitivity and specificity of molecular biology techniques for the genetic differentiation of species have promoted great advances in the identification of fungal species. Frequently, amplification of the internal transcribed spacer region (ITS1-5.8S-ITS2) of ribosomal DNA (rDNA) by the polymerase chain reaction (PCR) combined with sequencing procedure and similarity analysis between the sequences obtained and those available in GenBank has been employed (Magnani et al., 2005) to answer systematic questions and determine phylogenetic heredity (Ragozine, 2008). 
Considering the shortage of information about endophytes from P. hispidum, this study aimed to isolate the fungal endophyte community associated with $P$. hispidum leaves from a tropical forest remnant and to describe the endophytic diversity based on sequencing of the ITS1-5.8S-ITS2 region of rDNA and phylogenetic analysis.

\section{MATERIAL AND METHODS}

\section{Plant collection}

Mature, symptomless, undamaged leaves of $P$. hispidum were randomly collected from "Horto Florestal Dr. Luiz Teixeira Mendes", a 37 hectare forest remnant in the municipality of Maringá, Paraná State, southern Brazil (2326'5.10”S, 5157'59.46”W). The temperature of the collection month (January 2009) ranged between $19.8^{\circ}$ and $29.4^{\circ} \mathrm{C}$ with an average temperature of $24.8^{\circ} \mathrm{C}$ and relative humidity of about $76 \%$. The collected material was immediately processed.

\section{Isolation of endophytic fungi}

Leaves were first washed in running tap water, aqueous solution $0.01 \%$ Tween 80 (Synth) and autoclaved distilled water (twice) to remove epiphyllous debris. Leaves were rinsed with $70 \%$ ethanol for 1 min, surface-disinfected with sodium hypochlorite solution (3\% available $\mathrm{Cl}^{-}$) for $3 \mathrm{~min}$, and rinsed once in 70\% ethanol (30 s) and twice in sterile distilled water. The disinfection process was checked by spreading $100 \mu \mathrm{L}$ of the last water used on Petri dishes containing PDA (potato dextrose agar) culture medium supplemented with tetracycline $(50 \mu \mathrm{g} / \mathrm{mL}$ in $50 \%$ ethanol) to prevent bacterial growth.

Leaves were cut into 3-5- $\mathrm{mm}^{2}$ fragments and equally placed on PDA dishes with tetracycline added. All dishes were incubated at $28^{\circ} \mathrm{C}$ in biochemical oxygen demand (BOD) for seven days and periodically checked. Afterward, the colonization frequency (\%) was determined: (number of fragments colonized by fungi / total number of fragments) x 100 .

For the purification process the isolated fungi were transferred to PDA dishes and grown for seven days, then a $5-\mathrm{mm}^{2}$ fragment of each endophytic culture was macerated in $1 \mathrm{~mL} 0.01 \%$ Tween 80 , spread $(100 \mu \mathrm{L})$ on PDA dishes and incubated for $24 \mathrm{~h}$. Immediately after, monosporic colonies were transferred to new PDA dishes and also grown for seven days. When necessary, the purification process was repeated until generating pure cultures. Endophytic fungi were maintained on PDA.

\section{Molecular identification of endophytic fungus isolates}

Genomic DNA was extracted as described by Pamphile and Azevedo (2002), except that endophytes were previously grown for seven days in dishes with potato dextrose broth. The DNA concentration and purity were checked by spectrophotometer Genesys 10UV (OD $260 / 280 \mathrm{~nm}$ ) and the DNA integrity was checked by electrophoresis on $1 \%$ agarose gel using a High DNA Mass Ladder (Invitrogen) as the DNA molecular weight standard. The final concentration of DNA was adjusted to $10 \mathrm{ng} / \mathrm{mL}$.

PCR amplification of the ITS1-5.8S-ITS2 region of rDNA was performed as described 
by Magnani et al. (2005), using primers ITS1 and ITS4 (White et al., 1990). Negative controls, containing all reagents except for genomic DNA, were prepared in each PCR. PCR products were purified with GFX PCR DNA and Gel Band Purification kits (Amersham Biosciences) in accordance with manufacturer instructions. The samples were prepared for sequencing according to Magnani et al. (2005), except that only primer ITS1 was employed, and sequenced in a MegaBACE ${ }^{\mathrm{TM}} 1000$ automated sequencer (Amersham Biosciences) with $1 \mathrm{kV} / 90 \mathrm{~s}$ and 7 $\mathrm{kV} / 240 \mathrm{~min}$ as injection and electrophoresis conditions, respectively.

For the identification of fungal isolates, percentages of sequence identity and coverage were compared with available sequences in GenBank (http://www.ncbi.nlm.nih.gov) using BLASTN, to search for the closest matched sequences. The sequence data from this study were submitted to GenBank under accession Nos. JF766988 to JF767008.

For phylogenetic analysis, a dendrogram was made with the sequences obtained in this study and those available in GenBank. Sequences were aligned using ClustalX with the default settings and the dendrogram was made with version 4 of the MEGA program (Tamura et al., 2007) with grouping by neighbor-joining method (Saitou and Nei, 1987), using p-distance matrix for nucleotides with the pairwise gap deletion option and with 10,000 bootstrapping (BP) repetitions.

\section{RESULTS}

\section{Isolation and molecular identification of endophytic fungi from $P$. hispidum}

From the 500 leaf fragments sampled from P. hispidum, a colonization frequency of $96.59 \%$ was obtained. The absence of microbial growth in the negative control ensured the efficiency of the surface-disinfection process. From the 483 endophytes that colonized fragments, 138 were randomly isolated and grouped into 66 morphogroups, according to their morphological characteristics, such as colony coloration, pigment formation, development, and growth of mycelial colony on PDA. Ninety-eight endophytes, with at least two fungal isolates from each morphogroup when they existed (some morphogroups were constituted by a single endophyte), were randomly selected and purified for DNA extraction.

At the end of sequencing of the ITS1-5.8S-ITS2 region, it was possible to identify 21 from the 98 fungal endophytic isolates, belonging to 18 different morphogroups and 11 genera (Alternaria, Bipolaris, Colletotrichum, Glomerella, Guignardia, Lasiodiplodia, Marasmius, Phlebia, Phoma, Phomopsis, and Schizophyllum); one isolate was identified until the ordinal level (Diaporthales) (Table 1). The most frequent genus was Bipolaris, with $23.81 \%$ of identified endophytes belonging to it, followed by Colletotrichum (19.05\%), Alternaria and Phomopsis $(9.53 \%$ each). Other genera were represented by a single identified isolate $(4.76 \%)$. The percentages of identity among the obtained sequences and those available in GenBank ranged from 90 to $100 \%$.

\section{Phylogenetic analysis based on data of rDNA sequencing}

Phylogenetic analysis separated the fungal endophytes in five clades (Figure 1). The first clade comprises fungi from the phylum Ascomycota, class Sordariomycetes and Hypocreomycetidae incertae sedis, with representatives from the genus Colletotrichum and its tele- 
omorph Glomerella. The isolate G56-91 (90\% identity with Glomerella cingulata FJ904831.1 at BLAST) was grouped to Glomerella sp (GQ334409.1) with 93\% in BP analysis and grouped to the other Colletotrichum/Glomerella fungi with 99\% BP. The isolate G10-57 (97\% identity with $C$. gloeosporioides GU066653.1 at BLAST) was subgrouped (99\% BP) in the subclade that grouped about $73 \%$ of $C$. gloesporioides from NCBI. The isolates G13-109 (95\% identity with $C$. theobromicola GU994355.1 at BLAST) and G54-136 (99\% identity with C. boninense GU994382.1 at BLAST) were grouped with $95 \%$ BP and both of them were grouped to the isolate G08-64 (97\% identity with Colletotrichum sp EU734583.1 at BLAST) with 76\% BP. These three isolates were grouped to the other fungi from this clade with $99 \% \mathrm{BP}$.

Table 1. Isolated and identified endophytes with relationship to the genus or species and the identity percentage found in the NCBI (National Center for Biotechnology Information) website.

\begin{tabular}{|c|c|c|}
\hline Endophytes & Closely related fungal sequence & Identity $(\%)$ \\
\hline G02-02 & Guignardia mangiferae HM222959.1 & 98 \\
\hline G03-90 & Bipolaris sorokiniana HM195260.1 & 96 \\
\hline G08-64 & Colletotrichum sp EU734583.1 & 97 \\
\hline G10-57 & Colletotrichum gloeosporioides GU066653.1 & 97 \\
\hline G13-109 & Colletotrichum theobromicola GU994355.1 & 95 \\
\hline G14-29 & Alternaria mali FJ418189.1 & 98 \\
\hline G14-86 & Alternaria sp HQ328034.1 & 98 \\
\hline G20-20 & Lasiodiplodia theobromae GU228527.1 & 93 \\
\hline $\mathrm{G} 25-51$ & Schizophyllum commune AF249388.1 & 98 \\
\hline G25-59 & Phlebia sp AB210077.1 & 90 \\
\hline G25-95 & Marasmius cladophyllus HQ248211.1 & 98 \\
\hline $\mathrm{G} 27-60$ & Phomopsis sp EU878429.1 & 91 \\
\hline G29-79 & Phomopsis sp FJ827629.1 & 96 \\
\hline G30-30 & Bipolaris sp DQ123600.1 & 93 \\
\hline G31-31 & Bipolaris sp DQ123600.1 & 96 \\
\hline G32-118 & Bipolaris sp GU017499.1 & 100 \\
\hline G34-52 & Phoma herbarum FJ904851.1 & 96 \\
\hline G54-136 & Colletotrichum boninense GU994382.1 & 99 \\
\hline G55-117 & Bipolaris sorokiniana HM195251.1 & 94 \\
\hline G56-91 & Glomerella cingulata FJ904831.1 & 90 \\
\hline G65-65 & Diaporthales sp HQ117860.1 & 98 \\
\hline
\end{tabular}

The second clade comprises fungi from the phylum Ascomycota, class Sordariomycetes and order Diaporthales, with representatives from the genus Phomopsis and its teleomorph Diaporthe. The isolate G27-60 (91\% identity with Phomopsis sp EU878429.1 at BLAST) was grouped to Phomopsis sp (EU878429.1 and EU878433.1) with 59\% BP. The isolate G2979 (96\% identity with Phomopsis sp FJ827629.1 at BLAST) was grouped to Phomopsis sp (EU256482.1) with 50\% BP and to the other fungi from this clade with $79 \% \mathrm{BP}$. The isolate G65-65 (98\% identity with Diaporthales sp HQ117860.1 at BLAST) was grouped to Diaporthales sp (HQ117860.1) with 91\% BP.

The third clade comprises fungi from the phylum Ascomycota, class Dothideomycetes and order Botryosphaeriales, with representatives from the genera Guignardia and Phyllosticta (teleomorph/anamorph), Lasiodiplodia and Botryosphaeria (anamorph/teleomorph). The isolate G02-02 (98\% identity with Guignardia mangiferae HM222959.1 at BLAST) was grouped to G. mangiferae (HM222958.1) with $93 \%$ BP and both of them were grouped with G. mangiferae isolates from this clade with $72 \%$ BP. The isolate G20-20 (93\% identity with $L$. theobromae GU228527.1 at BLAST) was subgrouped to the L. theobromae isolates with $99 \%$ BP. 
A

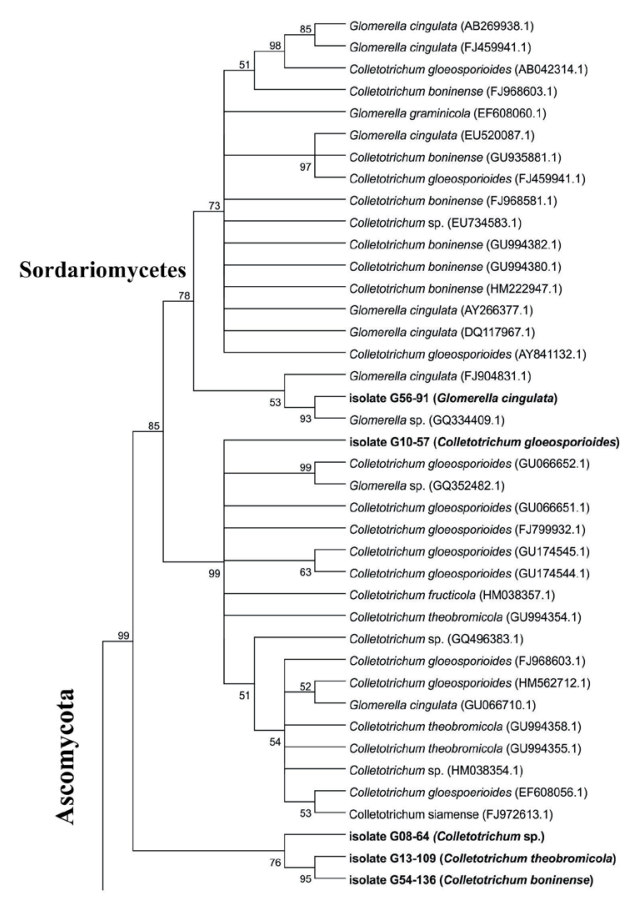

B

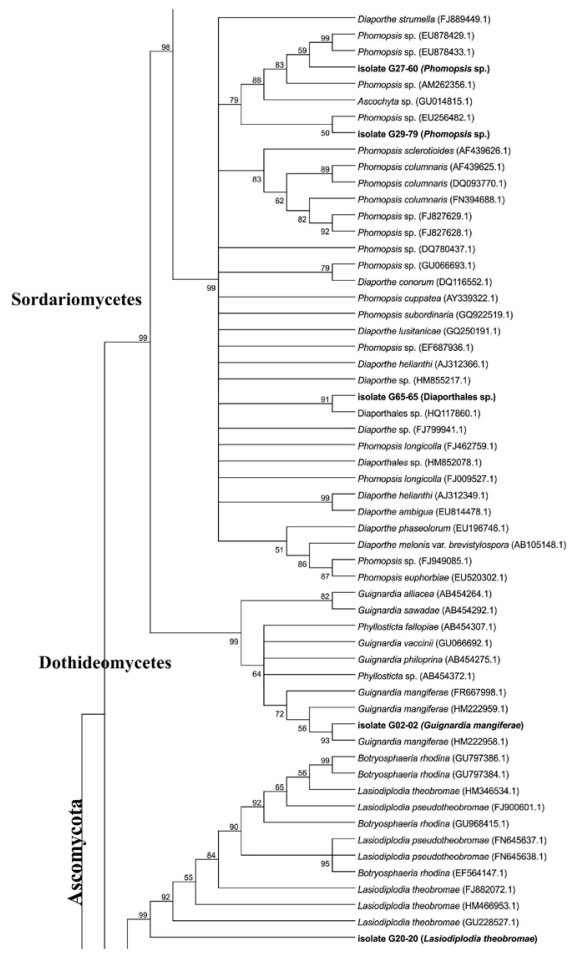

Clade I

Incertae sedis

Figure 1. Continued on next page.

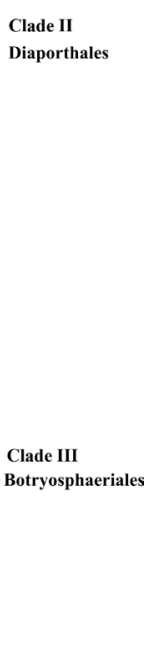

Genetics and Molecular Research 11 (2): 1575-1585 (2012) 


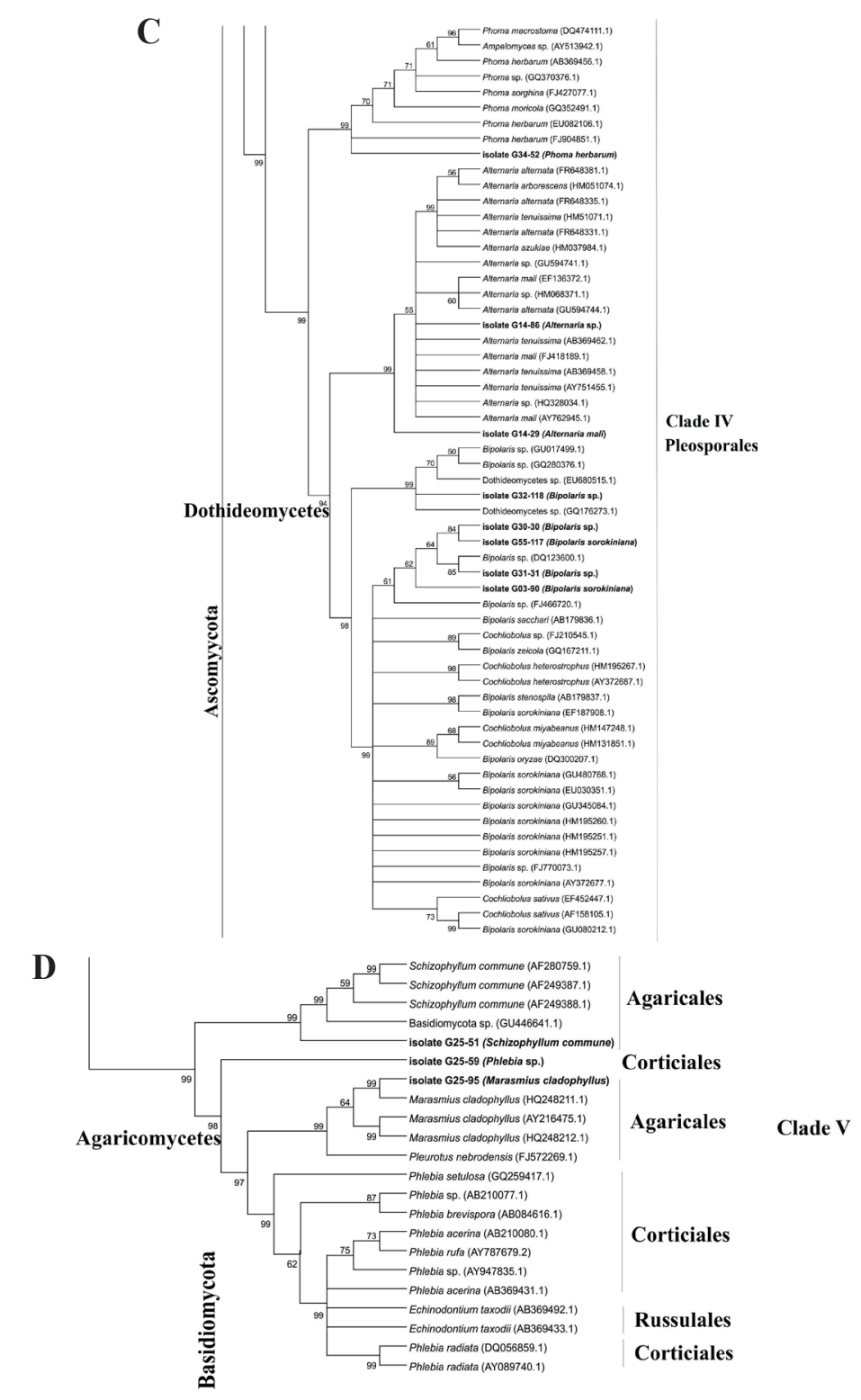

Figure 1. Phylogenetic tree constructed with endophytic sequences from Piper hispidum (in bold) and sequences from GenBank (indicated by database code), using the neighbor-joining method using p-distance for nucleotides, with the pairwise gap deletion option. The numbers above and underneath each knot indicate the frequency (in percentage) of each branch in bootstrap analyses of 10,000 replicates. A. Clade I comprises the phylum Ascomycota, class Sordariomycetes, with endophytes identified as Colletotrichum and Glomerella. B. Clade II comprises the phylum Ascomycota, class Dothideomycetes and order Diaporthales, with endophytes identified as Phomopsis and Diaporthales; clade III comprises the phylum Ascomycota, class Dothideomycetes and order Botryosphaeriales, with endophytes identified as Guignardia mangiferae and Lasiodiplodia theobromae. C. Clade IV comprises the phylum Ascomycota, class Dothideomycetes and order Pleosporales, with endophytes identified as Phoma, Alternaria and Bipolaris. D. Clade V comprises the phylum Basidiomycota and class Agaricomycetes, with endophytes identified as Schizophyllum, Phlebia and Marasmius. 
The fourth clade comprises fungi from the phylum Ascomycota, class Dothideomycetes and order Pleosporales, with representatives from the genera Phoma, Alternaria, Bipolaris, and its teleomorph Cochliobolus. The isolate G34-52 (96\% identity with Phoma herbarum FJ904851.1 at BLAST) was grouped to P. herbarum (FJ804851.1) with 99\% BP. The isolate G14-86 (98\% identity with Alternaria sp HQ328034.1 at BLAST) was grouped with 99\% BP to the Alternaria isolates, including G14-29 (98\% identity with A. mali FJ418189.1 at BLAST).

The isolate G32-118 (100\% identity with Bipolaris sp GU017499.1 at BLAST) was grouped to some Bipolaris and Dothideomycetes isolates with $99 \%$ BP. The isolate G30-30 (93\% identity with Bipolaris sp DQ123600.1 at BLAST) presented a major proximity with the endophyte G55-117 (94\% identity with B. sorokiniana HM195251.1 at BLAST) with 84\% BP. The isolates G31-31 (96\% identity with Bipolaris sp DQ123600.1 at BLAST) was grouped to Bipolaris sp (DQ123600.1) with 85\% BP and the isolate G03-90 (96\% identity with B. sorokiniana HM195260.1 at BLAST) was grouped to the Bipolaris fungi already cited with $62 \%$ BP.

The fifth clade comprises fungi from the phylum Basidiomycota and class Agaricomycetes. The isolate G25-51 (98\% identity with Schizophyllum commune AF249388.1 at BLAST) was subgrouped to the other $S$. commune fungi with $99 \%$ BP. The isolate G25-59 (90\% identity with Phlebia sp AB21000077.1 at BLAST) was subgrouped to the other Phlebia fungi with 98\% BP, whereas the isolate G25-95 (98\% identity with Marasmius cladophyllus HQ248211.1 at BLAST) was grouped to M. cladophyllus (HQ248211.1) with 99\% BP.

\section{DISCUSSION}

According to Petrini et al. (1982) and Carroll (1988), cultures of surface-disinfected leaves and stems from healthy plants reveal a high diversity of fungal species growing subcuticularly or within host tissues. Sánchez Márquez et al. (2007) consider that surface-disinfection methods should be used in all endophyte studies because they are efficient at eliminating epiphytes, maintaining the viability of fungi with an endophytic growth habit. The surfacedisinfection process with sodium hypochlorite solution $\left(3 \%\right.$ available $\left.\mathrm{Cl}^{-}\right)$for 3 min was also used by Araújo et al. (2001) and Procópio et al. (2009), as it is efficient on surface disinfecting plant samples for isolation of both endophytic fungi and bacteria.

Bernardi-Wenzel et al. (2010) state that the foliar fragment size may interfere in the number of endophytic isolates, since if the fragment is large, the microorganisms of the fringes may impair the growth of the most distant ones; therefore, the use of small fragments (about $5-7 \mathrm{~mm}^{2}$ ) is more efficient for isolating studies. Similarly to these authors, in the current study foliar fragments of up to $5 \mathrm{~mm}^{2}$ were employed.

The colonization of endophytes may be influenced by many factors, such as climatic conditions and plant age (Arnold and Herre, 2003). The colonization frequency of $96.59 \%$ obtained in P. hispidum leaves is similar to other recent studies about tropical angiosperms (Bernardi-Wenzel et al., 2010; Gazis and Chaverri, 2010). The high rates of infection in mature leaves from tropical trees are considered as a result of the apparent universal receptivity of tropical plants to colonization by endophytic fungi, in addition to the exposure to a high abundance of inoculum in the air column (Van Bael et al., 2005; Arnold, 2002, 2008), since environments with a reduced exposure to aerial fungal inoculum may present a low incidence of endophytic infection (Sánchez Márquez et al., 2011). 
Some endophytes isolated in the present study have been also observed in several other studies (Araújo et al., 2001; Sieber, 2007; Ding et al., 2010; González and Tello, 2011; Sun et al., 2011). On the contrary, some genera isolated in this study are rarely reported as endophytes, such as the genus Phlebia, which is more associated with soil contamination of specimens (Ragozine, 2008).

In the current study, eight genera were represented each by only a single identified endophyte. Sánchez Márquez et al. (2011) recently emphasized that many species are isolated only once in an endophyte survey, being considered rare in the host plant. The interactions between plants and rare species may represent unstable associations that possibly only occur when a given plant and fungal phenotype are confronted.

There is a shortage of information about the identification of endophytic fungi from Piper plants. Fungi from the genus Alternaria were also isolated as endophytes from P. barbatum, by Yandry et al. (2006), using morphological techniques of identification. Other genera isolated by these authors were Aspergillus and Epicoccum; endophytes from the classes Coelomycetes and Zygomycetes were also isolated; however, most of the isolates (70\%) were Mycelia sterilia.

In a study with the tropical seagrass Enhalus acoroides, Sakayaroj et al. (2010) identified 10 genera and two species of endophytes while others could only be identified at the family and ordinal levels. Similar to our study, the Bipolaris genus was found. These authors pointed to the fact that a major limitation for molecular identification of endophytes is the limited number of sequences and lack of named sequences from the GenBank database for comparison. Moreover, some authors stated that sequences can be blasted in GenBank without absolute certainty that these species have been correctly identified (Cai et al., 2009; Pinruan et al., 2010; Botella and Diez, 2011).

However, Albrectsen et al. (2010) considered that where ITS information is available in the database a correct taxonomical match is more likely. In the analyses of these authors the BLAST results for the $18 \mathrm{~S}$ sequences were, in most cases, sufficiently strong to suggest affinity even to the genus. In our analyses it was possible to identify, at species levels, $52.38 \%$ from the total of endophytes molecularly identified, with BLAST identity ranging from 90 to $100 \%$. Considering a safety margin of isolates that are at least $95 \%$ identical to sequences available in GenBank, the percentage of $P$. hispidum isolates identified at the species level was approximately $38.1 \%$.

P. hispidum endophytes may be divided into two main groups: the first one comprises 18 ascomycetous isolates (85.71\%) whereas the second group comprises three basidiomycetes (14.29\%). A predominance of ascomycetes was reported in other studies (Sánchez Márquez et al., 2007; Albrectsen et al., 2010; Gazis and Chaverri, 2010; Sakayaroj et al., 2010; González and Tello, 2011; Rocha et al., 2011).

Sieber (2007) pointed out that representatives of both the bitunicate ascomycetes (orders Dothideales, Pleosporales and Mycosphaerellales) and the Xylariales order can be dominant in endophytical communities from angiosperms and gymnosperms. Pleosporales was the most frequent order (38.1\% of identified endophytes) in the $P$. hispidum leaves sampled. Most of identified endophytes belong to the class Dothideomycetes (42.86\%).

The current study indicated a large endophytical colonization of $P$. hispidum leaves, as expected for angiosperms from tropical areas. The division of endophytes into 66 morphogroups suggests that there is a diversity of endophytes in the sampled leaves, although it was 
possible to identify only 21 of the 98 endophytic isolates. The sequencing and phylogenetic analysis revealed the presence of common and uncommon endophytes in P. hispidum leaves. For phylogenetic analysis, the bootstrapping percentages higher than $90 \%$ confirmed the molecular identification of some isolates (G56-91, G10-57, G13-109, and G54-136) at the genus level. The molecular identification of other isolates (G34-52 and G25-95) was confirmed at the species level, with rates of $99 \%$ BP.

\section{ACKNOWLEDGMENTS}

The authors thank the Laboratório de Biologia Molecular e Estrutural - COMCAP/ UEM for the sequencing of ITS1-5.8S-ITS2 regions and CAPES (Coordenação de Aperfeiçoamento de Pessoal de Ensino Superior) for the master's scholarship.

\section{REFERENCES}

Albrectsen BR, Björkén L, Varad A and Hagner A (2010). Endophytic fungi in European aspen (Populus tremula) leaves - diversity, detection, and a suggested correlation with herbivory resistance. Fungal Divers. 41: 17-28.

Araújo WL, Maccheroni W Jr, Aguilar-Vildoso CI, Barroso PA, et al. (2001). Variability and interactions between endophytic bacteria and fungi isolated from leaf tissues of citrus rootstocks. Can. J. Microbiol. 47: 229-236.

Aravind R, Kumar A, Eapen SJ and Ramana KV (2009). Endophytic bacterial flora in root and stem tissues of black pepper (Piper nigrum L.) genotype: isolation, identification and evaluation against Phytophthora capsici. Lett. Appl. Microbiol. 48: 58-64.

Arnold AE (2002). Neotropical Fungal Endophytes: Diversity and Ecology. Doctoral thesis, University of Arizona, Tucson.

Arnold AE (2008). Endophytic Fungi: Hidden Components of Tropical Community Ecology. In: Tropical Forest Community Ecology (Schnitzer S and Carson W, eds.). Blackwell Scientific, London, 254-271.

Arnold AE and Herre EA (2003). Canopy cover and leaf age affect colonization by tropical fungal endophytes: Ecological pattern and process in Theobroma cacao (Malvaceae). Mycologia 95: 388-398.

Arnold AE and Engelbrecht BMJ (2007). Fungal endophytes nearly double minimum leaf conductance in seedlings of a tropical tree. J. Trop. Ecol. 23: 369-372.

Arnold AE, Maynard Z, Gilbert GS and Coley PD (2000). Are tropical fungal endophytes hyperdiverse? Ecol. Lett. 3: 267-274.

Banerjee D (2011). Endophytic fungal diversity in tropical and subtropical plants. Res. J. Microbiol. 6: 54-62.

Bernardi-Wenzel J, Garcia A, Rubin Filho CJ, Prioli AJ, et al. (2010). Evaluation of foliar fungal endophyte diversity and colonization of medicinal plant Luehea divaricata (Martius et Zuccarini). Biol. Res. 43: 375-384.

Botella L and Diez J (2011). Phylogenic diversity of fungal endophytes in Spanish stands of Pinus halepensis. Fungal Divers. 47: 9-18.

Cai L, Hyde KD, Taylor PWJ and Weir BS (2009). A polyphasic approach for studying Colletotrichum. Fungal Divers. 39: 183-204.

Carroll G (1988). Fungal endophytes in stems and leaves: from latent pathogens to mutualistic symbionts. Ecology 69: 2-9.

Ding T, Jiang T, Zhou J, Xu L, et al. (2010). Evaluation of antimicrobial activity of endophytic fungi from Camptotheca acuminata (Nyssaceae). Genet. Mol. Res. 9: 2104-2112.

Gazis R and Chaverri P (2010). Diversity of fungal endophytes in leaves and stems of wild rubber trees (Hevea brasiliensis) in Peru. Fungal Ecol. 3: 240-254.

González V and Tello ML (2011). The endophytic mycota associated with Vitis vinifera in central Spain. Fungal Divers. 47: 29-42.

Guimarães EF and Giordano LCS (2004). Piperaceae do Nordeste brasileiro I: estado do Ceará. Rodriguésia 55: 21-46.

Hanada RE, Pomella AW, Costa HS, Bezerra JL, et al. (2010). Endophytic fungal diversity in Theobroma cacao (cacao) and T. grandiflorum (cupuaçu) trees and their potential for growth promotion and biocontrol of black-pod disease. Fungal Biol. 114: 901-910.

Herre EA, Van Bael SA, Maynard Z and Robbins N (2005). Tropical Plants as Chimera: Some Implications of Foliar Endophytic Fungi for the Study of Host Plant Defense, Physiology, and Genetics. In: Biotic Interactions in the 
Tropics (Burslem DFRP, Pinard MA and Hartley SE, eds.). Cambridge University Press, Cambridge, 226-237.

Magnani M, Fernandes T, Prete CEC and Homechim M (2005). Molecular identification of Aspergillus spp. isolated from coffee beans. Sci. Agric. 62: 45-49.

Pamphile JA and Azevedo JL (2002). Molecular characterization of endophytic strains of Fusarium verticillioides (=Fusarium moniliforme) from maize (Zea mays L.). World J. Microbiol. Biotechnol. 18: 391-396.

Pamphile JA, Rocha CLMSC and Azevedo JL (2004). Co-transformation of a tropical maize endophytic isolate of Fusarium verticillioides (synonym F. moniliforme) with gusA and nia genes. Genet. Mol. Biol. 27: 253-258.

Petrini O, Stone J and Carroll FE (1982). Endophytic fungi in evergreen shrubs in western Oregon: a preliminary study. Can. J. Bot. 60: 789-796.

Pinruan U, Rungjindamai N, Choeyklin R and Lumyong S (2010). Occurrence and diversity of basidiomycetous endophytes from the oil palm, Elaeis guineensis in Thailand. Fungal Divers. 41: 71-88.

Pinto LSRC, Azevedo JL, Pereira JO and Carneiro Vieira ML (2000). Symptomless infection of banana and maize by endophytic fungi impairs photosynthetic efficiency. New Phytol. 147: 609-615.

Procópio RE, Araujo WL, Maccheroni W Jr and Azevedo JL (2009). Characterization of an endophytic bacterial community associated with Eucalyptus spp. Genet. Mol. Res. 8: 1408-1422.

Ragozine VK (2008). Analyses of Ribosomal DNA Internal Transcribed Spacer Sequences from Juglans nigra and LeafAssociated Fungi in Zoar Valley, NY. Master's thesis, Youngstown State University, Youngstown.

Rocha ACS, Garcia D, Uetanabaro APT and Carneiro RTO (2011). Foliar endophytic fungi from Hevea brasiliensis and their antagonism on Microcyclus ulei. Fungal Divers. 47: 75-84.

Roíg y Mesa JT (1945). Plantas Medicinales. Ministerio de Agricultura: Serviço de Publicidade y Divulgación, Habana.

Saikkonen K and Helander SSM (2010). Defensive mutualism between plants and endophytic fungi? Fungal Divers. 41: 101-113.

Saitou N and Nei M (1987). The neighbor-joining method: a new method for reconstructing phylogenetic trees. Mol. Biol. Evol. 4: 406-425.

Sakayaroj J, Preedanon S and Supaphon O (2010). Phylogenetic diversity of endophyte assemblages associated with the tropical seagrass Enhalus acoroides in Thailand. Fungal Divers. 42: 27-45.

Sánchez Márquez S, Bills GF and Zabalgogeazcoa I (2007). The endophytic mycobiota of the grass Dactylis glomerata. Fungal Divers. 27: 171-195.

Sánchez Márquez S, Bills GF, Herrero N and Zabalgogeazcoa I (2011). Non-systemic fungal endophytes of grasses. Fungal Ecol. 5: 289-297.

Sieber T (2007). Endophytic fungi in forest trees: are they mutualists? Fungal Biol. Rev. 21: 75-89.

Sun X, Guo LD and Hyde KD (2011). Community composition of endophytic fungi in Acer truncatum and their role in decomposition. Fungal Divers. 47: 85-95.

Tamura K, Dudley J, Nei M and Kumar S (2007). MEGA4: molecular evolutionary genetics analysis (MEGA) software version 4.0. Mol. Biol. Evol. 24: 1596-1599.

Van Bael SA, Maynard Z, Robbins N and Bischoff J (2005). Emerging Perspectives on the Ecological Roles of Endophytic Fungi in Tropical Plants. In: The Fungal Community: Its Organization and Role in the Ecosystem (White JF Jr, Dighton J and Oudemans P, eds.). Marcel-Dekker, New York, 181-191.

White TJ, Bruns TD, Lee S and Taylor JW (1990). Amplification and Direct Sequencing of Fungal Ribosomal RNA Genes for Phylogenetics. In: PCR Protocols: a Guide to Methods and Applications (Innis MA, Gelfand DH, Sninsky JJ and White TJ, eds). Academic Press, San Diego, 315-322.

Yandry RRJ, Fernandez ED, Rodolfi M and Solveig T (2006). Actividad antagónica de hongos endófitos de plantas medicinales del Ecuador sobre bacterias patógenas. Bol. Micol. 21: 49-53. 